\title{
Functional Outcome and Patient Satisfaction After Displaced Intra-Articular Calcaneal Fractures: A Comparison Among \\ Open, Percutaneous, and Nonoperative Treatment
}

\author{
A. Siebe De Boer ${ }^{1}$, Esther M.M. Van Lieshout, MSc, $\mathrm{PhD}^{1}$, Dennis Den Hartog, MD, \\ $\mathrm{PhD}^{1}$, Bas Weerts, $\mathrm{MD}^{2}$, Michael H.J. Verhofstad, MD, PhD ${ }^{1}$, Tim Schepers, MD, PhD ${ }^{1,3}$ \\ ${ }^{1}$ Trauma Research Unit, Department of Surgery, Erasmus MC, University Medical Center Rotterdam, \\ Rotterdam, The Netherlands \\ 2 Department of Orthopedic Surgery, Erasmus MC, University Medical Center Rotterdam, Rotterdam, The \\ Netherlands \\ 3 Trauma Unit, Department of Surgery, Academic Medical Center, Amsterdam, The Netherlands
}

Level of Clinical Evidence: 3

Keywords: calcaneus, complication, conservative treatment, joint depression, open reduction internal fixation, trauma 


\section{ABSTRACT}

The aim of the present study was to compare the outcomes of patients with a displaced calcaneal fracture treated by open reduction and internal fixation (ORIF), percutaneous treatment, or nonoperative methods. A retrospective cohort study was conducted at a level I trauma center of patients with a displaced intra-articular calcaneal fracture treated from January 1, 2002 to December 31, 2011. The patient-reported outcome measures included the Foot Function Index, American Orthopaedic Foot and Ankle Society hindfoot scale, Short Form-36, the EQ-5D from the EuroQol Group, and a 10-point visual analog scale.

Clinical data were collected from 169 patients, and questionnaires were obtained from 78 patients (18 nonoperatively, 27 ORIF, and 33 percutaneously). The late intervention rate was significantly greater in the percutaneous group $(\mathrm{N}=18 ; 30 \%)$ than in the ORIF group $(\mathrm{N}=6 ; 12 \%)$ or the nonoperative group $(\mathrm{N}=8 ; 13 \% ; p=.030)$. Significantly more disability was reported in the nonoperative group (median Foot Function Index score, 40 points) than in the ORIF group (median, 16 points; $p=.010$ ) or in the percutaneous group (median, 21 points; $p=.034$ ). In conclusion, the operatively treated patients (ORIF and percutaneous treatment) reported better functional outcome scores (Foot Function Index and American Orthopaedic Foot and Ankle Society hindfoot scale) than did the nonoperatively treated patients. 


\section{INTRODUCTION}

Displaced intra-articular calcaneal fractures will occur mainly $(60 \%)$ in patients who are still in their wage-earning period (i.e., 30 to 50 years old). The interval to work resumption has often been 5 to 10 months (1). A considerable number of patients will not be able to resume work within 1 year $(2,3)$. These fractures can remain symptomatic for 1 to 2 years and can lead to the need for secondary arthrodesis in up to $16 \%$ of the nonoperatively treated patients $(1,4)$.

In the Netherlands, the most frequently applied treatment modalities have been open reduction and internal fixation (ORIF; 46\%), nonoperative treatment (39\%), and percutaneous treatment (10\%) (5).

Six meta-analyses of 4 randomized controlled trials, 1 prospective cohort study, and 3 retrospective studies have indicated a trend toward an overall improved outcome (e.g., work resumption, prevalence of complications, functional outcome, and shoe adjustments) in patients treated with ORIF (6-11). However, because most studies were powered for specific outcomes and used different outcome scores, no definitive answer to the best treatment can be given. To minimize surgical complications such as infection or nerve damage after calcaneal fracture repair, different minimally invasive, percutaneous techniques have been introduced $(12,13)$. The percutaneous techniques have not been investigated as extensively as ORIF.

The primary aim of the present study was to examine the effect of ORIF, percutaneous, and nonoperative treatment using the Foot Function Index in adult patients who had sustained a displaced intra-articular calcaneal fracture. In addition, the effect of treatment on health-related quality of life, overall patient satisfaction, interval to work resumption, and the prevalence of complications and late interventions was examined. 


\section{PATIENTS AND METHODS}

All consecutive patients with a displaced intra-articular calcaneal fracture ("International Classification of Diseases, 10th revision" code S92.06) (14) treated at a level I trauma center from January 1, 2002 to December 31, 2011 were considered eligible for the present retrospective case series. The patients were identified from patient registries using the Diagnosis Related Group for both diagnosis (code 236; calcaneal fracture) and surgery (code 339732; operative treatment calcaneal fracture). Fracture management consisted of ORIF, percutaneous treatment, or nonoperative treatment.

The patients were treated by a general orthopedic surgeon (Monday and Thursday) or an orthopedic trauma surgeon (the rest of the week). Both had different local preferences. Because of the retrospective nature of our study, the treatment choice could not be determined on a case basis. A general orthopedic surgeon (B.W.) primarily conducted the nonoperative management (19 of 24 patients, $79 \%$ ), and the orthopedic trauma surgeons (D.D.H., T.S.) preferred operative management (105 of 145 patients, 72\%). Until June 1, 2005, the primary operative management in this group was percutaneous treatment (33 of 33 patients, 100\%). After June 1, 2005, the policy was changed to ORIF (48 of 72 patients, 67\%), based on the available evidence. Surgeon experience with a certain technique and preference was the decisive factor between the choice of ORIF and percutaneous treatment. The other reasons for surgery included open or fracture dislocation.

The inclusion criteria for patient selection were an intra-articular calcaneal fracture with more than $2 \mathrm{~mm}$ of displacement (i.e., Sanders type II to IV) and age 16 to 70 years. The exclusion criteria were primary arthrodesis or amputation, a Gustilo grade III open fracture, known alcohol or drug abuse, and wheelchair-bound patients with a neurologic disability before, or caused by, the injury. Secondary arthrodesis was considered a 
complication of primary treatment and was included in the analysis. Functional outcome was determined after the patients had provided written informed consent. Patients with American Society of Anesthesiologists class IV, those who had died, those with an unknown address or who had moved abroad, patients without trauma radiographs, and patients with an ongoing psychiatric illness or insufficient comprehension of the Dutch or English language to understand the study documents were also excluded. The local medical research ethics committee approved the study.

The patients received 1 of 3 different treatment modalities. Nonoperative management consisted of early non-weightbearing movement exercises or a plaster-ofParis cast. In this cohort, closed reduction by external compression (molding) was not performed.

The current reference standard for the treatment of displaced intra-articular calcaneal fractures is ORIF using an extended lateral approach. In most cases, a sharp $100^{\circ}$ to $110^{\circ}$ angled incision was used, with the vertical limb situated almost over the lateral edge of the Achilles tendon. The fracture was fixed using a titanium nonlocking calcaneal plate (Synthes Bettlach GmbH, Bettlach, Switzerland), using titanium 3.5-mm screws (15).

Percutaneous treatment, as described by Forgon and Zadravecz (16) and Zadravecz and Szekeres (17) was performed using three 3.0-mm Kirschner wires inserted through the tuberosity of the calcanei, talar neck, and cuboid. A distracting force was applied with an external fixator between the talus and calcaneus and between the talus and cuboid. Additional Kirschner wires were used as "joysticks" to reduce the posterior facet. Osteosynthesis was performed under fluoroscopic control with 6.5-mm cannulated Biomet (Biomet NL, Dordrecht, The Netherlands) or 7.3-mm Synthes (Synthes Bettlach GmbH) screws (18). 
The patient characteristics (i.e., gender, age at trauma, and comorbidities), fracture characteristics (i.e., affected side, trauma mechanism, and injury classification), treatment characteristics (i.e., treatment type, open or closed approach, and duration of plaster immobilization and non-weightbearing), complications, and late interventions were obtained from the electronic patient files. Data were collected by 5 of us (A.S.D.B., B.W., D.D.H., E.M.M.V.L., and T.S.).

Infectious complications were divided into superficial (i.e., minor) and deep (i.e., major) using the criteria from the Centers for Disease Control and Prevention to define a surgical site infection (19). Superficial infections could be treated nonoperatively (e.g., using oral antibiotics). Infections that required surgical intervention, readmission, or intravenous antibiotics were classified as deep infections (15).

The fractures were classified according to Essex-Lopresti (20) and Sanders et al (21). Böhler's angle was measured from the trauma and follow-up radiographs. The patients were queried regarding their dominant side, smoking habits, and work and sports activities at the age of trauma and at follow-up. Furthermore, the cosmetic result observed by the patients and any shoe adjustments were queried.

Patient-reported functional outcome was measured using validated questionnaires, which were sent by mail in September 2012. The Foot Function Index (primary outcome measure) was developed to measure the effect of the foot pathologic features on function in terms of pain, disability, and activity restriction (22). Twenty-three questions were scored from 1 (no pain, no difficulty, none of the time) to 10 (worst pain imaginable, so difficult or unable, all the time). The final maximum score could reach 100 points, with a higher score indicating more disability. 
The American Orthopaedic Foot and Ankle Society hindfoot scale includes 9 questions related to the subdomains of pain (1 question; 40 points), function (7 questions; 50 points), and alignment (1 question; 10 points) $(23,24)$. The maximum score is 100 .

The Short Form-36 (SF-36) questionnaire is a validated multipurpose health survey with 36 questions, representing 8 health domains that are combined into physical (PCS) and mental component summaries $(25,26)$. Scores from 0 to 100 points are derived for each domain, with lower scores indicating poorer function. The 1998 U.S. population was used as the reference because weighing factors for the PCS and mental component summary for the Dutch population are not available.

The EQ-5D is a validated questionnaire for health-related quality of life $(27,28)$. The EQ-VAS is a standard vertical 20 -cm visual analog scale for recording an individual's rating of their current health-related quality of life.

A 10-point visual analog scale, with 0 implying maximum dissatisfaction and 10, full satisfaction, was used to measure patient satisfaction with the overall outcome (18). The assessors of outcome (A.S.D.B., E.M.M.V.L.) were not involved in patient treatment. The data were analyzed by 2 of us (E.M.M.V.L. and T.S.) using the Statistical Package for the Social Sciences, version 20 (SPSS, Chicago, IL). Continuous data were found to deviate from a standard normal distribution (determined by inspecting frequency histograms and Q-Q plots) and are expressed as the median and first to third quartile $\left(\mathrm{P}_{25}\right.$ $\mathrm{P}_{75}$ ). Kruskal-Wallis analysis of variance with post hoc pairwise comparison using a Mann-Whitney U test was performed to assess the statistical significance of the continuous data among the treatment groups. Categorical data are presented as numbers and percentages and were analyzed using chi-square tests. A $p$ value of $<.05$ was taken as the threshold of statistical significance. 


\section{RESULTS}

Demographic data

During the 10-year study period, 178 patients were treated for a displaced intraarticular calcaneal fracture. Nine patients were excluded from the present study because the Sanders classification could not be determined owing to missing radiologic images or insufficient image quality. Clinical data were collected for the remaining 169 patients. Of the 169 patients, 59 had been treated nonoperatively, 49 with ORIF, and 61 percutaneously (Table 1). The median age at trauma was 41 years $\left(\mathrm{P}_{25}-\mathrm{P}_{75} 33\right.$ to 50), and 130 patients (77\%) were male. The right calcaneus was fractured in 77 patients (46\%), and 23 patients (14\%) had a bilateral calcaneal fracture. The fractures had mainly resulted from a fall from a height $(\mathrm{n}=104 ; 62 \%)$ or low energy trauma $(\mathrm{n}=38 ; 22 \%)$. Of the 169 patients, 45 (27\%) had additional injuries. These baseline characteristics were not significantly different statistically among the 3 treatment groups.

When classified according to Essex-Lopresti (20), most of the fractures were of a joint depression type $(n=97 ; 57 \%)$ or a tongue type $(n=58 ; 34 \%)$. Comminuted fractures (not classifiable as joint depression or tongue type) were found in only 8 patients, 7 of which were treated with ORIF ( $p=.007)$. In each of the 3 groups, approximately $80 \%$ of fractures were Sanders type II.

Of the 169 patients, 108 were invited to complete the questionnaires because 61 had met an exclusion criterion (Fig. 1). Of the 108 patients, 78 returned the questionnaire (response rate $72 \%)$. Of the 78 respondents, $18(23.1 \%)$ had been treated nonoperatively, $27(34.6 \%)$ with ORIF, and $33(42.3 \%)$ percutaneously (Table 2). The respondents had patient and fracture characteristics similar to those for the total study population of 169 patients. The median body mass index was $25 \mathrm{~kg} / \mathrm{m} 2,10$ patients reported cardiovascular disease or diabetes, and $42 \%$ smoked at the time they had sustained the trauma. The 
patients' preferred (dominant) side was affected in $60 \%$ of the patients (Table 2). These characteristics were not significantly related to the treatment received. The same was true for the duration of plaster immobilization and non-weightbearing (Table 2).

Table 1: Characteristics and outcome for entire study population $(\mathrm{N}=169)$

\begin{tabular}{|c|c|c|c|c|c|}
\hline & $\begin{array}{l}\text { Overall } \\
(\mathrm{N}=169)\end{array}$ & $\begin{array}{c}\text { Non-operative } \\
(\mathbf{N}=59)\end{array}$ & $\begin{array}{l}\text { ORIF } \\
(\mathrm{N}=49)\end{array}$ & $\begin{array}{c}\text { Percutaneous } \\
(\mathrm{N}=61)\end{array}$ & P-value ${ }^{*}$ \\
\hline Age at trauma ${ }^{\dagger}$ (years) & $41(33-50)$ & $40(32-50)$ & $41(33-50)$ & $44(34-51)$ & $.573 / .542$ \\
\hline Male gender $\ddagger$ & $130(77 \%)$ & $46(78 \%)$ & $38(78 \%)$ & $46(75 \%)$ & $.939 / .825$ \\
\hline \multicolumn{6}{|l|}{ Affected side $\ddagger$} \\
\hline Right side & $77(46 \%)$ & $27(46 \%)$ & $24(49 \%)$ & $26(43 \%)$ & $.551 / .649$ \\
\hline Left side & $69(41 \%)$ & $21(36 \%)$ & $21(43 \%)$ & $27(44 \%)$ & \\
\hline Bilateral & $23(14 \%)$ & $11(19 \%)$ & $4(8 \%)$ & $8(13 \%)$ & \\
\hline \multicolumn{6}{|l|}{ Trauma mechanism $\ddagger$} \\
\hline LET & $38(22 \%)$ & $13(22 \%)$ & $13(27 \%)$ & $12(20 \%)$ & $.130 / .453$ \\
\hline HET fall from height & $104(62 \%)$ & $32(54 \%)$ & $32(65 \%)$ & $40(66 \%)$ & \\
\hline HET other & $5(3 \%)$ & $1(2 \%)$ & $1(2 \%)$ & $3(5 \%)$ & \\
\hline Other & $1(1 \%)$ & $0(0 \%)$ & $1(2 \%)$ & $0(0 \%)$ & \\
\hline Unknown & $21(12 \%)$ & $13(22 \%)$ & $2(4 \%)$ & $6(10 \%)$ & \\
\hline Concomitant injuries $\ddagger$ & $45(27 \%)$ & $17(29 \%)$ & $12(24 \%)$ & $16(26 \%)$ & $.238 / .528$ \\
\hline \multicolumn{6}{|l|}{ Essex-Lopresti classification $\ddagger$} \\
\hline Tongue Type & $58(34 \%)$ & $18(31 \%)$ & $17(35 \%)$ & $23(38 \%)$ & $.007 \S / .011^{\S}$ \\
\hline Joint depression & $97(57 \%)$ & $36(61 \%)$ & $25(51 \%)$ & $36(59 \%)$ & \\
\hline Comminuted & $8(5 \%)$ & $1(2 \%)$ & $7(14 \%)$ & $0(0 \%)$ & \\
\hline \multicolumn{6}{|l|}{ Sanders classification ${ }^{\ddagger}$} \\
\hline Sanders II & $132(78 \%)$ & $48(81 \%)$ & $38(78 \%)$ & $46(75 \%)$ & $.291 / .919$ \\
\hline Sanders III & $27(16 \%)$ & $5(8 \%)$ & $10(20 \%)$ & $12(20 \%)$ & \\
\hline Sanders IV & $7(4 \%)$ & $4(7 \%)$ & $1(2 \%)$ & $2(3 \%)$ & \\
\hline Surgical delay ${ }^{\dagger}$ (days) & $5(2-7)$ & N.A. & $6(3-11)$ & $2(1-6)$ & N.A. $/<.001 \S$ \\
\hline Clinical follow-up ${ }^{\dagger}$ (months) & $12(5-19)$ & $9(1-16)$ & $13(9-19)$ & $13(6-25)$ & $.001 \S \| / .907$ \\
\hline Follow-up > $30 \mathrm{~d}^{\ddagger}$ & $149(88 \%)$ & $44(75 \%)$ & $47(96 \%)$ & $58(95 \%)$ & $<.001 \S / 1.000$ \\
\hline Adverse event (incl. infection) $\ddagger$ & $56(33 \%)$ & $14(24 \%)$ & $14(29 \%)$ & $28(46 \%)$ & $.026 \S / .077$ \\
\hline Infection $^{2}$ & $16(9 \%)$ & N.A. & $8(16 \%)$ & $8(13 \%)$ & N.A. / .787 \\
\hline Surgical site infection & $7(44 \%)$ & N.A. & $5(63 \%)$ & $2(25 \%)$ & N.A. / .315 \\
\hline Deep infection & $9(56 \%)$ & N.A. & $3(38 \%)$ & $6(75 \%)$ & \\
\hline $\begin{array}{l}\text { Late intervention } \\
\quad(\text { excl. implant removal }) \ddagger\end{array}$ & $32(19 \%)$ & $8(14 \%)$ & $6(12 \%)$ & $18(30 \%)$ & $.030 \S / .037 \S$ \\
\hline Subtalar arthrodesis & $19(59 \%)$ & $7(88 \%)$ & $0(0 \%)$ & $12(67 \%)$ & $.002^{\S} / .004 \S$ \\
\hline Exostosis resection & $5(16 \%)$ & $1(13 \%)$ & $1(17 \%)$ & $3(17 \%)$ & \\
\hline Wound debridement & $5(16 \%)$ & $0(0 \%)$ & $2(33.3)$ & $3(17 \%)$ & \\
\hline Revision surgery & $3(9 \%)$ & $0(0 \%)$ & $3(50.0)$ & $0(0 \%)$ & \\
\hline Implant removal ${ }^{\ddagger}$ & $59(35 \%)$ & N.A. & $19(39 \%)$ & $40(66 \%)$ & N.A. / .007§ \\
\hline Time until implant removal $^{\dagger}(\text { weeks })^{1}$ & $28(17-52)$ & N.A. & $55(36-69)$ & $22(16-30)$ & N.A. / <.001§ \\
\hline
\end{tabular}

Abbreviations: HET, high energy trauma; LET, low energy trauma; NA, not applicable; ORIF, open reduction and internal fixation.

Data presented as median (25th percentile to 75 th percentile) or $\mathrm{n}(\%)$.

* First $p$ value from comparison of the 3 treatment groups; second $p$ value for comparison of 2 surgical groups.

$\dagger$ Kruskal-Wallis analysis of variance.

$\$$ Chi-square analysis.

$\S$ Difference found between nonoperative group and ORIF and percutaneous groups (both $\mathrm{p}=.001$ ).

$\|$ Statistically significant. 
The period of clinical follow-up differed significantly among the 3 treatment groups for the overall population of 169 patients (Kruskal-Wallis $\mathrm{p}=.001$; Table 1 ). The median clinical follow-up at the outpatient department was shorter in the nonoperative group (median 9 months, $\mathrm{P}_{25}-\mathrm{P}_{75} 1$ to 16 ) than in the ORIF group (median 13 months, $\mathrm{P}_{25}$ $\mathrm{P}_{75} 10$ to $\left.19 ; p=.001\right)$ or the percutaneous group (13 months, $\mathrm{P}_{25}-\mathrm{P}_{75} 6$ to $\left.25 ; \mathrm{p}=.001\right)$. In the nonoperative group, $75 \%$ of the patients were seen at regular intervals extending to 30 days. In the ORIF and percutaneous groups, $96 \%$ and $95 \%$ of patients were seen at the outpatient department for longer than 30 days. Transfer to a hospital abroad and refusal were the main reasons for not returning to the outpatient department. Only the patients who had attended the outpatient department for their entire clinical follow-up period were invited for the present study to report on their long-term functional outcome (Table 3). This resulted in monitoring for longer than 30 days in $99 \%$ of the responders, with a median follow-up period of 14 months. A total of 108 patients were sent the questionnaires, of whom 78 responded (72\% response rate).

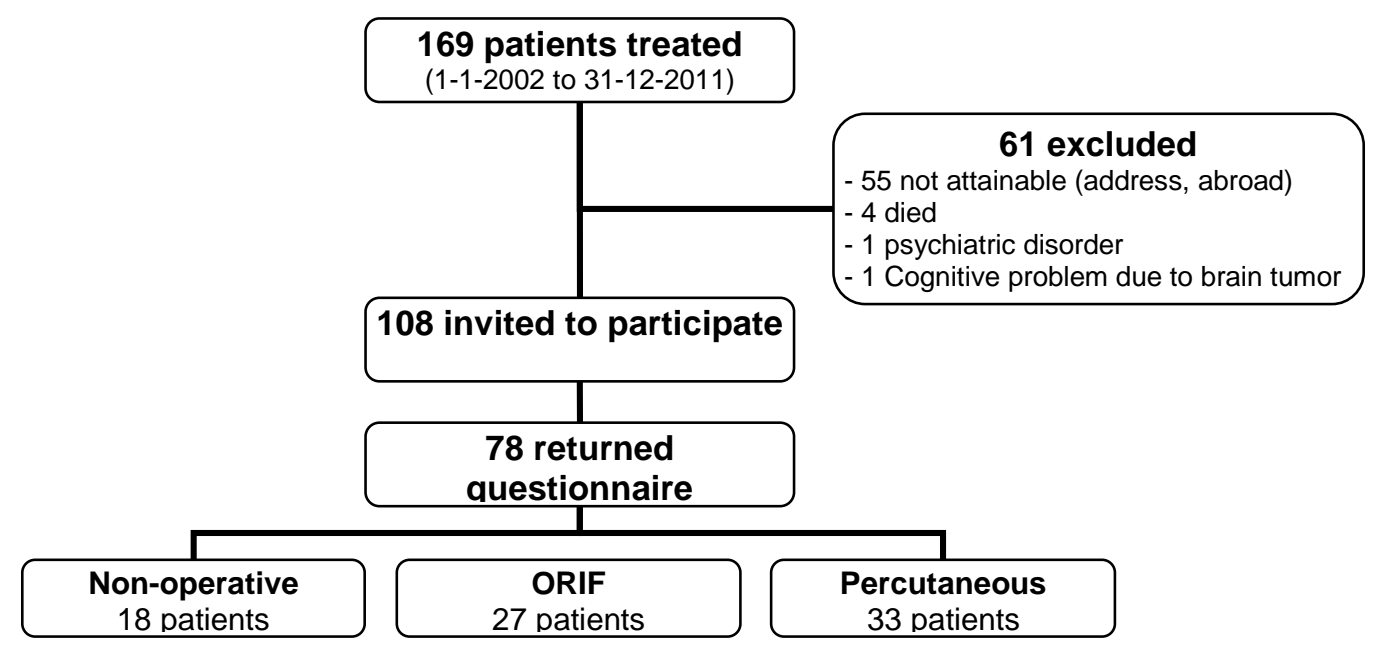

Fig. 1 Study flowchart. ORIF, open reduction and internal fixation. 
Table 2: Characteristics of patients who returned the questionnaire $(\mathrm{N}=78)$

\begin{tabular}{|c|c|c|c|c|c|}
\hline & $\begin{array}{l}\begin{array}{l}\text { Overall } \\
(\mathrm{N}=78)\end{array} \\
\end{array}$ & $\begin{array}{c}\text { Non-operative } \\
(\mathrm{N}=18)\end{array}$ & $\begin{array}{l}\text { ORIF } \\
(\mathbf{N}=27)\end{array}$ & $\begin{array}{c}\text { Percutaneous } \\
(\mathrm{N}=33)\end{array}$ & P-value* \\
\hline Age at trauma (years) ${ }^{\dagger}$ & $46(36-55)$ & $44(34-59)$ & $45(34-56)$ & $47(40-54)$ & $.697 / .435$ \\
\hline Male gender $\ddagger$ & $59(76 \%)$ & $14(78 \%)$ & $20(74 \%)$ & $25(76 \%)$ & $.960 / 1.000$ \\
\hline $\operatorname{BMI}\left(\mathrm{kg} / \mathrm{m}^{2}\right)^{\dagger}$ & $25(22-27)$ & $24(22-27)$ & $23(22-27)$ & $26(23-28)$ & $.174 / .070$ \\
\hline \multicolumn{6}{|l|}{ Affected side ${ }^{2}$ : } \\
\hline Right side & $33(42 \%)$ & $6(33 \%)$ & $15(52 \%)$ & $13(39 \%)$ & $.511 / .292$ \\
\hline Left side & $36(46 \%)$ & $9(50 \%)$ & $12(44 \%)$ & $15(45 \%)$ & \\
\hline Bilateral & $9(12 \%)$ & $3(17 \%)$ & $1(4 \%)$ & $5(15 \%)$ & \\
\hline Dominant side affected ${ }^{\ddagger}$ & $47(60 \%)$ & $13(72 \%)$ & $15(56 \%)$ & $19(58 \%)$ & $.491 / 1.000$ \\
\hline \multicolumn{6}{|l|}{ Trauma mechanism ${ }^{\ddagger}$} \\
\hline LET & $20(26 \%)$ & $3(17 \%)$ & $10(37 \%)$ & $7(21 \%)$ & $.479 / .311$ \\
\hline HET fall from height & $47(60 \%)$ & $11(61 \%)$ & $15(56 \%)$ & $21(64 \%)$ & \\
\hline HET other & $2(3 \%)$ & $1(6 \%)$ & $0(0 \%)$ & $1(3 \%)$ & \\
\hline Other & $1(1 \%)$ & $0(0 \%)$ & $1(4 \%)$ & $0(0 \%)$ & \\
\hline Unknown & $8(10 \%)$ & $3(17 \%)$ & $1(4 \%)$ & $4(12 \%)$ & \\
\hline Concomitant injury $\ddagger$ & $18(23 \%)$ & $7(39 \%)$ & $4(15 \%)$ & $7(21 \%)$ & $.253 / .457$ \\
\hline Co-morbidity $\ddagger$ & $10(13 \%)$ & $4(22 \%)$ & $0(0 \%)$ & $6(18 \%)$ & $.044 \S / .028 \S$ \\
\hline Cardiovascular disease & $6(8 \%)$ & $3(17 \%)$ & $0(0 \%)$ & $3(9 \%)$ & $.112 / .245$ \\
\hline Diabetes mellitus & $4(5 \%)$ & $1(6 \%)$ & $0(0 \%)$ & $3(9 \%)$ & $.282 / .245$ \\
\hline Smoking at age of trauma ${ }^{\ddagger}$ & $33(42 \%)$ & $9(50 \%)$ & $9(33 \%)$ & $15(45 \%)$ & $.482 / .430$ \\
\hline \multicolumn{6}{|l|}{ Essex-lopresti classification $\ddagger$} \\
\hline Tongue Type & $35(45 \%)$ & $8(44 \%)$ & $13(48 \%)$ & $14(42 \%)$ & $.060 / .053$ \\
\hline Joint depression & $39(50 \%)$ & $10(56 \%)$ & $10(37 \%)$ & $19(58 \%)$ & \\
\hline Comminuted & $4(5 \%)$ & $0(0 \%)$ & $4(15 \%)$ & $0(0 \%)$ & \\
\hline \multicolumn{6}{|l|}{ Sanders classification ${ }^{\ddagger}$} \\
\hline Sanders II & $63(81 \%)$ & $16(89 \%)$ & $21(78 \%)$ & $26(79 \%)$ & $.236 / 1.000$ \\
\hline Sanders III & $14(18 \%)$ & $1(6 \%)$ & $6(22 \%)$ & $7(21 \%)$ & \\
\hline Sanders IV & $1(1 \%)$ & $1(6 \%)$ & $0(0 \%)$ & $0(0 \%)$ & \\
\hline Surgical delay (days) ${ }^{\dagger}$ & $5(2-7)$ & N.A. & $6(3-8)$ & $3(1-7)$ & N.A. / .011§ \\
\hline Clinical follow-up (months) ${ }^{\dagger}$ & $14(9-24)$ & $13(6-24)$ & $16(12-21)$ & $14(8-30)$ & $.406 / .899$ \\
\hline Follow-up >30 days ${ }^{\ddagger}$ & $77(99 \%)$ & $17(94 \%)$ & $27(100 \%)$ & $33(100 \%)$ & $.185 / 1.000$ \\
\hline Plaster immobilization ${ }^{\ddagger}$ & $33(42 \%)$ & $10(56 \%)$ & $10(37 \%)$ & $13(39 \%)$ & $.230 / 1.000$ \\
\hline Plaster immobilization (weeks) $\ddagger$ & $6(3-10)$ & $9(4-13)$ & $4(1-8)$ & $6(6-9)$ & $.184 / .117$ \\
\hline Non-weight bearing (weeks) ${ }^{\dagger}$ & $12(8-13)$ & $12(8-14)$ & $12(12-13)$ & $12(7-13)$ & $.534 / .278$ \\
\hline
\end{tabular}

Abbreviations: HET, high energy trauma; LET, low energy trauma; NA, not applicable; ORIF, open reduction and internal fixation.

Data presented as median (25th percentile to 75 th percentile) or $\mathrm{n}(\%)$.

* First $p$ value from comparison of the 3 treatment groups; second $p$ value for comparison of 2 surgical groups.

$\dagger$ Kruskal-Wallis analysis of variance.

+ Chi-square analysis.

$\S$ Statistically significant. 
Of all 169 patients, 56 (33\%) experienced an adverse event, including 16 patients who developed an infection. The prevalence of adverse events was lowest in the nonoperative group $(\mathrm{n}=14 ; 24 \%)$ and greatest in the percutaneous group $(\mathrm{n}=28 ; 46 \%$; $p=.026 ;$ Table 1).

The difference in the prevalence of infections between the 2 operative methods was not significant 16\% (5 superficial and 3 deep) in the ORIF group and 13\% (2 superficial and 6 deep) in the percutaneous group ( $p=.315$ comparing superficial and deep infection in the operative groups; Table 1).

Late intervention (excluding implant removal) was performed in 32 patients (19\%). This percentage was significantly greater in the percutaneous group $(n=18 ; 30 \%)$ than in the ORIF group $(n=6 ; 12 \%)$ or nonoperative group $(n=8 ; 14 \% ; p=.030$; Table 1$)$.

The main late intervention (excluding implant removal) was subtalar arthrodesis in 19 patients, followed by exostosis resection in 5 , wound debridement in 5 , and revision of the osteosynthesis surgery in 3. Secondary arthrodesis was performed most frequently in the nonoperative group ( 7 of 8 patients undergoing late intervention; $88 \% ; p=.002$ ), followed by the percutaneous group ( 12 of $18,67 \% ; p=.004)$, and was not needed in the ORIF group.

Overall, arthrodesis was performed in $12 \%$ of patients in the nonoperative group and $20 \%$ of patients in the percutaneous group.

Implants were removed more frequently in the percutaneous group $(n=40 ; 66 \%)$ than in the ORIF group $(\mathrm{n}=19 ; 39 \% ; p=.007$; Table 1$)$. In addition to the lower prevalence of removal, the implants remained in situ for a significantly longer period in the ORIF group (median 55 weeks, $\mathrm{P}_{25}-\mathrm{P}_{75} 36$ to 69 ) than in the percutaneous group (median 22 weeks, $\mathrm{P}_{25}-\mathrm{P}_{75} 16$ to $30 ; p<.001$; Table 1). 


\section{Patient-reported Outcome Measures}

Questionnaires were completed by 78 patients (18 treated nonoperatively, 27 with ORIF, and 33 percutaneously). The Functional Foot Index score differed significantly among the treatment groups, with the greatest disability reported by the nonoperative group (median overall score 40 points; Table 4 and Fig. 2A). This was significantly greater than in the ORIF group (16 points; $p=.010$ ) or the percutaneous group (21 points; $p=$ .034). This was mainly attributable to differences in the subdomain activity limitation. The median American Orthopaedic Foot and Ankle Society hindfoot score ranged from 61 points in the nonoperative group to 81 in the percutaneous group. No statistically significant relation with treatment was found, neither in the overall score nor in the individual subdomains. However, the data suggested a trend in favor of operative treatment.

The median visual analog scale score for patient satisfaction ranged from 6.3 in the nonoperative group to 8.5 in the percutaneous group $(p>.05)$.

The SF-36 mental component summary score was similar in all treatment groups, with all median values within the normal range of $50 \pm 10$ points (Table 4 and Fig. 3B). However, the median PCS score was below the normality boundaries in the nonoperative group (38 points). The median PCS score was 50 in the percutaneous group and 52 in the ORIF group. The difference between the operative and nonoperative groups did not reach statistical significance ( $p=.050$; Table 4 and Fig. 3A).

The EQ-5D utility score (median $0.78, \mathrm{P}_{25}-\mathrm{P}_{75} 0.77$ to 0.93 ) and EQ-visual analog scale score (median $80, \mathrm{P}_{25}-\mathrm{P}_{75} 70$ to 89 ) were unrelated to the treatment used. 
Table 3: Clinical and cosmetic outcome in patients who returned the questionnaire $(\mathrm{N}=78)$

\begin{tabular}{|c|c|c|c|c|c|}
\hline & $\begin{array}{c}\text { Overall } \\
(\mathrm{N}=78)\end{array}$ & $\begin{array}{l}\text { Non-operative } \\
(\mathrm{N}=18)\end{array}$ & $\begin{array}{l}\text { ORIF } \\
(\mathbf{N}=\mathbf{2 7})\end{array}$ & $\begin{array}{c}\text { Percutaneous } \\
(\mathrm{N}=33)\end{array}$ & P-value* \\
\hline Follow-up (months) ${ }^{\dagger}$ & $76(54-88)$ & $78(51-88)$ & $56(28-76)$ & $88(68-107)$ & $<.001^{\ddagger} /<.001^{\ddagger}$ \\
\hline Working pre-fracture ${ }^{\ddagger}$ & $78(100 \%)$ & $18(100 \%)$ & $27(100 \%)$ & $33(100 \%)$ & $1.000 / 1.000$ \\
\hline \multicolumn{6}{|l|}{ Heaviness of work $\ddagger$} \\
\hline Heavy & $19(24 \%)$ & $6(33 \%)$ & $7(26 \%)$ & $6(18 \%)$ & $.515 / .777$ \\
\hline Mild & $33(42 \%)$ & $9(50 \%)$ & $10(37 \%)$ & $14(42 \%)$ & \\
\hline Light & $25(32 \%)$ & $3(17 \%)$ & $10(37 \%)$ & $12(36 \%)$ & \\
\hline Work resumption at FU & $63(81 \%)$ & $13(72 \%)$ & $26(96 \%)$ & $24(73 \%)$ & $.052 / .031^{\ddagger}$ \\
\hline Returned to same position & $44(56 \%)$ & $7(39 \%)$ & $21(78 \%)$ & $16(48 \%)$ & $.016^{\ddagger} / .043^{\ddagger}$ \\
\hline Returned to changed position & $19(24 \%)$ & $7(39 \%)$ & $5(19 \%)$ & $7(21 \%)$ & \\
\hline Unable to work due to complaints & $10(13 \%)$ & $4(22 \%)$ & $1(4 \%)$ & $5(15 \%)$ & \\
\hline Pension or unknown & $5(6 \%)$ & $0(0 \%)$ & $0(0.0)$ & $5(15 \%)$ & \\
\hline Sports activities pre-fracture $\ddagger$ & $37(47 \%)$ & $9(50 \%)$ & $14(52 \%)$ & $14(42 \%)$ & $.744 / .604$ \\
\hline Sports activities resumed at $\mathrm{FU}^{\ddagger}$ & $28(36 \%)$ & $5(28 \%)$ & $10(37 \%)$ & $13(39 \%)$ & $.702 / 1.000$ \\
\hline \multicolumn{6}{|l|}{ Walking barefoot $^{\ddagger}$} \\
\hline No problems & $46(59 \%)$ & $8(44 \%)$ & $19(70 \%)$ & $19(57 \%)$ & $.360 / .545$ \\
\hline With problems & $30(38 \%)$ & $10(56 \%)$ & $7(26 \%)$ & $13(39 \%)$ & \\
\hline Unable to do & $2(3 \%)$ & $0(0 \%)$ & $1(4 \%)$ & $1(3 \%)$ & \\
\hline Able to run $\ddagger$ & $43(55 \%)$ & $9(50 \%)$ & $17(63 \%)$ & $17(52 \%)$ & $.596 / .438$ \\
\hline Stiffness ${ }^{\ddagger}$ & $61(78 \%)$ & $18(100 \%)$ & $23(85 \%)$ & $20(61 \%)$ & $.003^{\ddagger} / .046^{\ddagger}$ \\
\hline Continuous & $31(51 \%)$ & $10(56 \%)$ & $12(52 \%)$ & $9(45 \%)$ & $.799 / .763$ \\
\hline Only in the morning & $30(49 \%)$ & $8(44 \%)$ & $11(48 \%)$ & $11(55 \%)$ & \\
\hline Change in shoe size $\ddagger$ & $22(28 \%)$ & $5(28 \%)$ & $8(30 \%)$ & $9(27 \%)$ & $.979 / 1.000$ \\
\hline Size change ${ }^{\dagger}$ & $1.0(1.0-1.0)$ & $1.0(-0.1-1.0)$ & $1.0(0.6-1.0)$ & $1.0(1.0-2.0)$ & $.184 / .131$ \\
\hline \multicolumn{6}{|l|}{ Changes in type of shoe $\ddagger$} \\
\hline Unchanged / mild concession & $53(68 \%)$ & $8(44 \%)$ & $21(78 \%)$ & $24(73 \%)$ & $.186 / .885$ \\
\hline Slight orthopedic changes (insoles) & $12(15 \%)$ & $5(28 \%)$ & $3(11 \%)$ & $4(12 \%)$ & \\
\hline Orthopedic shoes / shoes impossible & $13(17 \%)$ & $5(28 \%)$ & $3(11 \%)$ & $5(15 \%)$ & \\
\hline \multicolumn{6}{|l|}{ Change in foot shape ${ }^{\ddagger}$} \\
\hline Unchanged & $19(24 \%)$ & $3(17 \%)$ & $6(22 \%)$ & $10(30 \%)$ & $.440 / .295$ \\
\hline Mild changes & $42(54 \%)$ & $9(50 \%)$ & $18(67 \%)$ & $15(45 \%)$ & \\
\hline Moderate changes & $13(17 \%)$ & $4(22 \%)$ & $3(11 \%)$ & $6(18 \%)$ & \\
\hline Major changes & $4(5 \%)$ & $2(11 \%)$ & $0(0 \%)$ & $2(6 \%)$ & \\
\hline Adverse event (incl. infection) ${ }^{\ddagger}$ & $27(5 \%)$ & $4(22 \%)$ & $9(33 \%)$ & $14(42 \%)$ & $.345 / .595$ \\
\hline Infection ${ }^{\ddagger}$ & $11(14 \%)$ & N.A. & $5(19 \%)$ & $6(18 \%)$ & N.A. / 1.000 \\
\hline Surgical site infection & $6(55 \%)$ & N.A. & $4(80 \%)$ & $2(33 \%)$ & N.A. / .242 \\
\hline Deep infection & $5(45 \%)$ & N.A. & $1(20 \%)$ & $4(67 \%)$ & \\
\hline $\begin{array}{l}\text { Late intervention } \\
\qquad(\text { excl. implant removal }) \ddagger\end{array}$ & $14(18 \%)$ & $1(6 \%)$ & $4(15 \%)$ & $9(27 \%)$ & $.135 / .348$ \\
\hline Subtalar arthrodesis & $7(50 \%)$ & $1(100 \%)$ & $0(0 \%)$ & $12(67 \%)$ & $.187 / .057$ \\
\hline Exostosis resection & $2(14 \%)$ & $0(0 \%)$ & $1(25 \%)$ & $1(11 \%)$ & \\
\hline Wound debridement & $3(21 \%)$ & $0(0 \%)$ & $1(25 \%)$ & $2(22 \%)$ & \\
\hline Revision surgery & $2(14 \%)$ & $0(0 \%)$ & $2(50 \%)$ & $0(0 \%)$ & \\
\hline Implant removal $\left.\right|^{\ddagger}$ & $36(46 \%)$ & N.A. & $10(37.0)$ & $26(78.8)$ & N.A. / .001‡ \\
\hline Time until implant removal ${ }^{\dagger}$ (weeks) & $25(14-42)$ & N.A. & $55(30-71)$ & $23(12-32)$ & N.A. / .014 $\ddagger$ \\
\hline
\end{tabular}

Abbreviations: FU, follow-up; NA, not applicable; ORIF, open reduction and internal fixation.

Data presented as median (25th percentile to 75 th percentile) or $\mathrm{n}(\%)$.

* First $p$ value from comparison of the 3 treatment groups; second $p$ value for comparison of 2 surgical groups.

$\dagger$ Kruskal-Wallis analysis of variance. 
\$ Chi-square analysis.

$\S$ Statistically significant.

Work Resumption, Sports Resumption, and Cosmesis

All 78 patients had worked before their trauma, with no significant difference in the number of patients performing heavy labor among the treatment groups (Table 3). Patients in the ORIF group had resumed work in $96 \%$ of cases, significantly more than that in the percutaneous group $(75 \% ; p=.045)$. In the nonoperative group, $72 \%$ had returned to work at the time of completing the questionnaires. Because of the lower number of patients in the nonoperative group, this was not significantly different statistically from the rate in the operative groups. In addition to resuming work more often, a significantly greater proportion of the ORIF group had returned to the same position as before their injury.

Of the 78 patients, 37 (47\%) had participated in sports activities before their injury. At the last follow-up point, $28(76 \%)$ had resumed their sports activities, irrespective of the treatment type.

Also, 46 patients (59\%) were able to walk barefoot without problems, and 43 were able to run. Again, no relation with treatment was found. All patients in the nonoperative group reported stiffness of the ankle compared with $85 \%$ in the ORIF group and $61 \%$ in the percutaneous group ( $p=.003$; Table 3$)$. A total of 22 patients reported changes in shoe size, 59 reported a change in foot shape, and 25 reported the use of adjusted shoes at follow-up compared with before fracture. These findings were not associated with the treatment modality (Table 3).

\section{DISCUSSION}

In the present retrospective study, patients with a displaced intra-articular calcaneal fracture generally showed better functional outcomes after operative treatment (i.e., ORIF 
and percutaneous treatment) than after nonoperative treatment. Although a greater percentage of patients in the operative treatment groups had adverse events (including infections) and late interventions, the patient-reported outcome scores were better in the operative groups.

Table 4: Functional outcome and quality of life in patients who returned the questionnaire $(\mathrm{N}=78)$

\begin{tabular}{lcccc} 
Overall & Non-operative & ORIF & Percutaneous & P-value \\
$(\mathbf{N}=78)$ & $(\mathrm{N}=18)$ & $(\mathrm{N}=\mathbf{2 7})$ & $(\mathrm{N}=\mathbf{3 3})$ & \\
\hline
\end{tabular}

FFI:

$\begin{array}{lccccc}\text { Overall score } & 22(7-37) & 40(10-69) & 16(7-29) & 21(4-37) & .031 * \\ \text { Pain } & 26(9-48) & 47(11-68) & 20(9-41) & 21(2-45) & .063 \\ \text { Disability } & 19(8-50) & 52(11-70) & 16(1-34) & 17(2-47) & .077 \\ \text { Activity limitation } & 5(0-17) & 16(5-51) & 4(0-6) & 2(0-21) & .017 \dagger\end{array}$

AOFAS:

$\begin{array}{lccccc}\text { Overall score } & 77(59-89) & 61(43-78) & 76(64-85) & 81(66-95) & .060 \\ \text { Pain } & 30(20-30) & 20(20-30) & 30(20-30) & 30-(20-40) & .132 \\ \text { Function } & 40(32-47) & 31(20-41) & 41(34-47) & 42(34-48) & .069 \\ \text { Alignment } & 10(5-10) & 10(4-10) & 10(5-10) & 10(8-10) & .208\end{array}$

SF-36:

$\begin{array}{llllll}\text { PCS } & 48(36-54) & 38(27-53) & 52(42-57) & 50(38-54) & .050 \\ \text { MCS } & 57(47-61) & 54(45-60) & 58(56-61) & 57(45-62) & .490\end{array}$

EQ-5D:

$\begin{array}{lccccc}\text { EQUS } & 0.78(0.77-0.93) & 0.78(0.52-0.81) & 0.81(0.78-0.93) & 0.78(0.78-0.93) & .095 \\ \text { EQVAS } & 80(70-89) & 75(63-83) & 80(75-90) & 80(70-90) & .102\end{array}$

Patient satisfaction

(VAS)

$8.0(6.0-9.5)$

$6.3(3.8-9.5)$

$8.0(6.0-9.5)$

$8.5(7.0-10.0)$

.081

Abbreviations: AOFAS, American Orthopaedic Foot and Ankle Society hindfoot score; CI, confidence interval; EQ-5D, EuroQol-5D; EQUS, EuroQol utility score; EQVAS, EuroQoL visual analog scale; FFI, Foot Function Index; MCS, mental component summary; PCS, physical component summary; SF-36, Short Form-36; VAS, visual analog scale.

Data presented as median (25th to 75 th percentile).

Kruskal-Wallis analysis of variance used to assess statistical significance between the treatment groups, followed by post hoc pairwise comparisons using the Mann-Whitney U test if

significantly different.

* Statistically significant difference found between nonoperative and ORIF groups $(\mathrm{p}=.010)$ and nonoperative and percutaneous groups $(\mathrm{p}=.034)$.

$\uparrow$ Statistically significant difference found between nonoperative and ORIF groups $(p=.004)$ and nonoperative and percutaneous groups $(\mathrm{p}=.025)$. 
The nonoperatively treated patients reported more difficulties, such as shoe adjustments and hindfoot stiffness, and returned to work later. Of the 2 surgical procedures, the results were in favor of the ORIF treatment strategy. In the percutaneous group, more complications were seen, implants had to be removed more often, and patients required late intervention more frequently.

The published data have indicated that less invasive procedures might allow accelerated weightbearing, less joint stiffness, and greater patient' satisfaction compared with ORIF $(29,30)$. However, in the present study, ORIF provided better results. Almost one fifth of the percutaneously treated patients required secondary arthrodesis compared with none in the ORIF group. The $20 \%$ secondary arthrodesis rate after percutaneous treatment found in the present study was comparable to the previously reported $15 \%$ (18).

ORIF treatment has been known for infectious complications (1). In our study, $16 \%$ of patients in the ORIF group (8 of 49) experienced an infectious complication, which was not much different from the $13 \%$ in the percutaneous group. This infection rate of $13 \%$ was comparable to that in previous reports (31). Thus, the functional results in our study were not negatively affected by a learning curve of the surgeons in our medical center or a high infection rate. Although the implant removal rate of $39 \%$ for ORIF was comparable to that of other reports $(39 \%$ to $49 \%)(32,33)$, the $57 \%$ rate in the percutaneous group was much greater than the $12 \%$ reported previously (34). Considering the complaints of the patients in our study, it is plausible that the large screw head of the implants used for the percutaneous treatment was the cause of the high rate of implant removal (18,31). Especially for percutaneous treatment, less prominent implants (i.e., headless screws) should be considered $(35,36)$.

The response percentage for the different treatments groups was 31\% (18 of 59 patients) in the nonoperative group, 55\% (27 of 49 patients) in the ORIF group, and 54\% 
(33 of 61 patients) in the percutaneous group, indicating that fewer conservatively treated patients completed the questionnaires. The response percentage of both operative treatment groups was nearly identical.

Although nonoperative treatment of calcaneal fractures did not lead to the best results, it could still be a viable treatment modality given the noncompliance of some patients concerning mobilization advice during follow-up. Early studies $(37,38)$ showed that early exercise will be the best nonoperative modality. The nonoperatively treated patients reported inferior functional outcomes and more disability in the questionnaires than did the operatively treated patients. This might explain why the vast majority of late interventions in the nonoperative group were secondary arthrodesis.

Several comparative studies have described the results of ORIF and nonoperative management but did not use a standardized functional outcome scoring system (39-42). Studies comparing ORIF and nonoperative management that did use a disease-specific outcome score have shown conflicting results. Three studies reported a significantly greater outcome for operatively treated fractures (43-46). In another study, only a trend toward a better outcome in the operative group was seen (47). Two studies failed to find a significant difference $(48,49)$.

Just as with any retrospective study, we acknowledge the presence of limitations. The follow-up duration was different among the treatment groups because of a changes in the local protocol during the study period. The preferred surgical treatment changed from percutaneous to ORIF from 2005 onward. To some extent, the difference in functional outcome scores could have resulted from the differences in the interval between the trauma and questionnaire completion. With a median follow-up of 56 and 88 months, the ORIF and percutaneous groups had, overall, significantly better outcomes than did the nonoperatively treated patients, who had completed the questionnaires after 78 months. 
Clinical data could be retrieved for 9 months in the nonoperative group compared with 13 months in both operative groups. A shorter clinical follow-up period for the conservative group might have resulted in an underestimation of the true rate of complications and late interventions. This underestimation for the infectious complication rate in the present study was probably minimal, because more than $95 \%$ of the patients in the operative groups were followed up for at least 30 days, which we believed would be a relevant period for the identification of delayed or problematic wound healing.
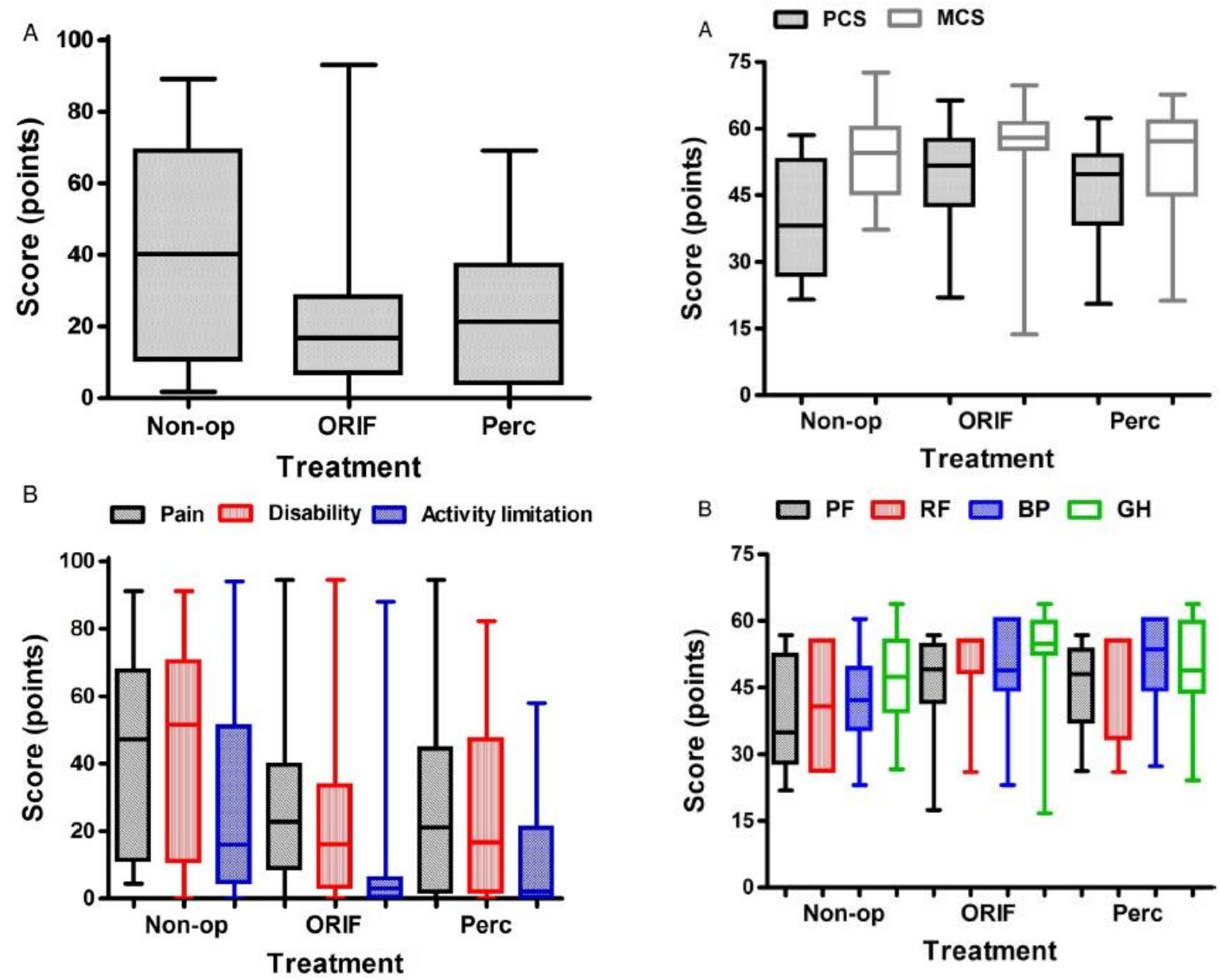

Fig. 2. (A) Foot Function Index total score. (B) Foot Function Index subdomain scores. Nonop, nonoperative; ORIF, open reduction and internal fixation; Perc, percutaneous.

Fig. 3. (A) Short Form-36 (SF-36) and physical component summary (PCS) scores. (B) SF36 physical component summary score for the subdomains. BP, bodily pain; GH, general health; PF, physical functioning; RF, role physical.

Another limitation was that of the 169 patients, only $108(64 \%)$ met the eligibility criteria for an invitation to complete the questionnaires. The clinical data from the sample of 108 
patients were similar to the data from the total population of 169 patients, supporting the idea that the invitees were representative of the total population. The response rate for the questionnaires was $72 \%$, consistent with that previously reported (50). This could have introduced some selection bias. Because the response percentage was comparable in each treatment group, the bias could not explain the differences found.

Minimally invasive, percutaneous treatment has often been chosen in patients with comorbidities, which might explain the complications in the percutaneous group. The differences in the complication rates between the percutaneous and ORIF groups should thus be interpreted with care. No difference in any of the observed patient characteristics (i.e., gender, age at trauma, smoking, diabetes mellitus and other comorbidities) or injury characteristics (i.e., affected side, trauma mechanism, injury classification, and concomitant injuries) among the treatment groups was noted in our study. Therefore, any consequent bias can be assumed to be, at most, marginal.

Concomitant injuries are not rare with calcaneal fractures. In the published data, there are indications that polytrauma patients with calcaneal fractures have had a worse clinical outcome than patients with isolated calcaneal fractures. The present study lacked statistical power to evaluate the relationship between polytrauma and functional outcome stratified by treatment modality.

In conclusion, our results have indicated that operatively treated patients report improved outcomes and better Foot Function Index and American Orthopaedic Foot and Ankle Society hindfoot scale score compared with the nonoperatively treated patients. These results support previous data (51-53). Patients treated with ORIF had the best outcome measures. In the present study, both functional and patient-related outcomes from the 3 different treatment strategies for displaced intra-articular calcaneal fractures were 
investigated. Overall, ORIF resulted in superior functional outcomes and greater patient satisfaction, with an acceptable complication rate and no secondary arthrodesis required.

Financial Disclosure: None reported.

Conflict of Interest: None reported. 


\section{REFERENCES}

1. Buckley R, Tough S, McCormack R, Pate G, Leighton R, Petrie D, Galpin R. Operative compared with nonoperative treatment of displaced intra-articular calcaneal fractures: a prospective, randomized, controlled multicenter trial. J Bone Joint Surg Am 84-A:1733-1744, 2002.

2. Pozo JL, Kirwan EO, Jackson AM. The long-term results of conservative management of severely displaced fractures of the calcaneus. J Bone Joint Surg Br 66:386-390, 1984.

3. Mortelmans LJ, Du Bois M, Donceel P, Broos PL. Impairment and return to work after intra-articular fractures of the calcaneus. Acta Chir Belg 102:329-333, 2002.

4. Crosby LA, Fitzgibbons T. Intraarticular calcaneal fractures. Results of closed treatment. Clin Orthop Relat Res 290:47-54, 1993.

5. Schepers T, van Lieshout EM, van Ginhoven TM, Heetveld MJ, Patka P. Current concepts in the treatment of intra-articular calcaneal fractures: results of a nationwide survey. Int Orthop 32:711-715, 2008.

6. AO Publishing. Intraarticular calcaneal fractures: operative management. Orthop Trauma Dir 2:9-16, 2004.

7. Bajammal S, Tornetta P III, Sanders D, Bhandari M. Displaced intra-articular calcaneal fractures. J Orthop Trauma 19:360-364, 2005.

8. Bridgman SA, Dunn KM, McBride DJ, Richards PJ. Interventions for treating calcaneal fractures. Cochrane Database Syst Rev:CD001161, 2000.

9. Gougoulias N, Khanna A, McBride DJ, Maffulli N. Management of calcaneal fractures: systematic review of randomized trials. Br Med Bull 92:153-167, 2009.

10. Randle JA, Kreder HJ, Stephen D, Williams J, Jaglal S, Hu R. Should calcaneal fractures be treated surgically? A meta-analysis. Clin Orthop Relat Res:217-227, 2000.

11. Bruce J, Sutherland A. Surgical versus conservative interventions for displaced intraarticular calcaneal fractures. Cochrane Database Syst Rev 1:CD008628, 2013.

12. Levine DS, Helfet DL. An introduction to the minimally invasive osteosynthesis of intra-articular calcaneal fractures. Injury 32(suppl 1)):SA51-SA54, 2001.

13. Biggi F, Di Fabio S, D'Antimo C, Isoni F, Salfi C, Trevisani S. Percutaneous calcaneoplasty in displaced intraarticular calcaneal fractures. J Orthop Traumatol 14:307-310, 2013.

14. The International Conference for the Tenth Revision of the International Classification of Diseases. Strengthening of Epidemiological and Statistical Services Unit. World Health Organization, Geneva. World Health Stat Q 43:204-245, 1990.

15. Schepers T, Den Hartog D, Vogels LM, Van Lieshout EM. Extended lateral approach for intra-articular calcaneal fractures: an inverse relationship between surgeon experience and wound complications. J Foot Ankle Surg 52:167-171, 2013.

16. Forgon M, Zadravecz G. Die Kalkaneusfraktur, Springer-Verlag, Berlin, 1990, pp. 1104.

17. Zadravecz G, Szekeres P. Late results of our treatment method in calcaneus fractures. Aktuelle Traumatol 14:218-226, 1984. in German.

18. Schepers T, Schipper IB, Vogels LM, Ginai AZ, Mulder PG, Heetveld MJ, Patka P. Percutaneous treatment of displaced intra-articular calcaneal fractures. J Orthop Sci 12:22-27, 2007.

19. Mangram AJ, Horan T,C, Pearson ML, Silver LC, Jarvis WR. Guideline for prevention of surgical site infection, 1999: Centers for Disease Control and Prevention 
(CDC) Hospital Infection Control Practices Advisory Committee. Am J Infect Control 27:97-132, 1999. quiz 133-134; discussion 196.

20. Essex-Lopresti $P$. The mechanism, reduction technique, and results in fractures of the os calcis. Br J Surg 39:395-419, 1952.

21. Sanders R, Fortin P, DiPasquale T, Walling A. Operative treatment in 120 displaced intraarticular calcaneal fractures. Results using a prognostic computed tomography scan classification. Clin Orthop Relat Res 290:87-95, 1993.

22. Budiman-Mak E, Conrad KJ, Roach KE. The Foot Function Index: a measure of foot pain and disability. J Clin Epidemiol 44:561-570, 1991.

23. Kitaoka HB, Alexander IJ, Adelaar RS, Nunley JA, Myerson MS, Sanders M. Clinical rating systems for the ankle-hindfoot, midfoot, hallux, and lesser toes. Foot Ankle Int 15:349-353, 1994.

24. Ibrahim T, Beiri A, Azzabi M, Best AJ, Taylor GJ, Menon DK. Reliability and validity of the subjective component of the American Orthopaedic Foot and Ankle Society clinical rating scales. J Foot Ankle Surg 46:65-74, 2007.

25. Ware JE Jr, Sherbourne CD. The MOS 36-item short-form health survey (SF-36). I. Conceptual framework and item selection. Med Care 30:473-483, 1992.

26. Aaronson NK, Muller M, Cohen PD, Essink-Bot ML, Fekkes M, Sanderman R, Sprangers MA, te Velde A, Verrips E. Translation, validation, and norming of the Dutch language version of the SF-36 Health Survey in community and chronic disease populations. J Clin Epidemiol 51:1055-1068, 1998.

27. Brooks R. The Measurement and Valuation of Health Status Using EQ-5D: A European Perspective, Kluwer Academic Publishers, Dordrecht, The Netherlands, 2003.

28. Lamers LM, Stalmeier PF, McDonnell J, Krabbe PF, van Busschbach JJ. Measuring the quality of life in economic evaluations: the Dutch EQ-5D tariff. Ned Tijdschr Geneeskd 149:1574-1578, 2005.

29. Chen L, Zhang G, Hong J, Lu X, YuanW. Comparison of percutaneous screw fixation and calcium sulfate cement grafting versus open treatment of displaced intraarticular calcaneal fractures. Foot Ankle Int 32:979-985, 2011.

30. Wu Z, Su Y, Chen W, Zhang Q, Liu Y, Li M, Wang H, Zhang Y. Functional outcome of displaced intra-articular calcaneal fractures: a comparison between open reduction/internal fixation and a minimally invasive approach featured an anatomical plate and compression bolts. J Trauma Acute Care Surg 73:743-751, 2012.

31. Tomesen T, Biert J, Frolke JP. Treatment of displaced intra-articular calcaneal fractures with closed reduction and percutaneous screw fixation. J Bone Joint Surg Am 93:920-928, 2011.

32. Benirschke SK, Kramer PA. Wound healing complications in closed and open calcaneal fractures. J Orthop Trauma 18:1-6, 2004.

33. Harvey EJ, Grujic L, Early JS, Benirschke SK, Sangeorzan BJ. Morbidity associated with ORIF of intra-articular calcaneus fractures using a lateral approach. Foot Ankle Int 22:868-873, 2001.

34. DeWall M, Henderson CE, McKinley TO, Phelps T, Dolan L, Marsh JL. Percutaneous reduction and fixation of displaced intra-articular calcaneus fractures. J Orthop Trauma 24:466-472, 2010.

35. Gokce A. Stabilization of calcaneus fractures in a closed manner with a distraction screw. Eklem Hastalik Cerrahisi 20:62, 2009.

36. Kadas I, Szita J, Zadravecz G, Hangody L, Doczi J. Stabilization of calcaneus fractures in a closed manner with a distraction screw. Joint Dis Relat Surg 19:45-49, 2008. 
37. Barnard L, Odegard JK. Conservative approach in the treatment of fractures of the calcaneus. J Bone Joint Surg Am 37-A:1231-1236, 1955.

38. Carothers RG, Lyons JF. Early mobilization in treatment of os calcis fractures. Am J Surg 83:279-280, 1952.

39. Kundel K, Funk E, Brutscher M, Bickel R. Calcaneal fractures: operative versus nonoperative treatment. J Trauma 41:839-845, 1996.

40. Nouraei MH, Moosa FM. Operative compared to non-operative treatment of displaced intra-articular calcaneal fractures. J Res Med Sci 16:1014-1019, 2011.

41. Paul M, Peter R, Hoffmeyer P. Fractures of the calcaneum. A review of 70 patients. $\mathbf{J}$ Bone Joint Surg Br 86:1142-1145, 2004.

42. Robb CA, Deans V, Iqbal MJ, Cooper JP. Comparison of non-operative and surgical treatment of displaced calcaneal fractures. Foot 17:169-173, 2007.

43. Basile A. Operative versus nonoperative treatment of displaced intra-articular calcaneal fractures in elderly patients. J Foot Ankle Surg 49:25-32, 2010.

44. Leung KS, Yuen KM, Chan WS. Operative treatment of displaced intra-articular fractures of the calcaneum. Medium-term results. J Bone Joint Surg Br 75:196-201, 1993.

45. Zwipp H, Rammelt S, Barthel S. Calcaneal fractures-open reduction and internal fixation (ORIF). Injury 35(suppl 2):SB46-SB54, 2004.

46. Schofer M, Schoepp C, R€ulander C, Kortmann HR. Operative und konservative Behandlung der Kalkaneusfrakturen. Trauma Berufskrankh 7:S156-S161, 2005.

47. Kennedy JG, Jan WM, McGuinness AJ, Barry K, Curtin J, Cashman WF, Mullan GB. An outcomes assessment of intra-articular calcaneal fractures, using patient and physician's assessment profiles. Injury 34:932-936, 2003.

48. Thornes BS, Collins AL, Timlin M, Corrigan J. Outcome of calcaneal fractures treated operatively and non-operatively: the effect of litigation on outcomes. Ir J Med Sci 171:155-157, 2002.

49. Sharma V, Dogra A. Sanders type II calcaneum fracturesdsurgical or conservative treatment? A prospective randomized trial. J Clin Orthop Trauma 2:35-38, 2011.

50. Murnaghan ML, Buckley RE. Lost but not forgotten: patients lost to follow-up in a trauma database. Can J Surg 45:191-195, 2002.

51. O'Farrell DA, O'Byrne JM, McCabe JP, Stephens MM. Fractures of the os calcis: improved results with internal fixation. Injury 24:263-265, 1993.

52. Parmar HV, Triffitt PD, Gregg PJ. Intra-articular fractures of the calcaneum treated operatively or conservatively. A prospective study. J Bone Joint Surg Br 75:932-937, 1993.

53. Thordarson DB, Krieger LE. Operative vs. nonoperative treatment of intra-articular fractures of the calcaneus: a prospective randomized trial. Foot Ankle Int 17:2-9, 1996. 